\title{
Consensual Unions and Fertility
}

\author{
JARL LINDGREN
}

Senior Research Associate, Docent

The Population Research Institute of Väestöliitto

\section{MARKETTA RITAMIES}

Research Associate

The Population Research Institute of Väestöliitto

\section{ANNELI MIETTINEN}

\section{Research Assistant}

The Population Research Institute of Väestöliitto

Helsinki, Finland

\begin{abstract}
This article examines how consensual unions affect the childbearing of couples who live in a marriage which has been preceded by premarital cohabitation. The study is focused on women under the age of 30 when they started their first union. It is based on three five-year cohorts who started living together in 1970-1984. The material used is from a survey carried out in 1989.

The study deals with the pattern and frequency of giving birth to the first child by comparing the childbearing of the directly married with those whose marriage was preceded by cohabitation. By comparing the total number of children borne by women who have lived in an extra-marital cohabitation with different national means, the effect of pre-marital cohabitation on fertility is estimated.

The study has shown that the total number of children in families is related to the length of premarital cohabitation. The couples who have lived longer without marriage tend to have less children than the directly married.
\end{abstract}

Keywords: consensual union, marriage, fertility, Finland

\section{Introduction}

During the last few decades living in consensual unions has become more and more common. While only about one percent of all unions in Finland were consensual unions in the beginning of the 1970 s, the corresponding number at the end of the $1980 \mathrm{~s}$ was 17 percent. At the same time the proportion of children born outside marriage has increased quite rapidly. In the beginning of the 1970 s one tenth of all children 
born were "illegitimate" while in 1990 the proportion born outside marriage was one fourth. As most consensual unions end in marriage after one or two years, most children born outside marriage sooner or later become legitimate children. In 1990 only eight percent of all children aged 0-17 years lived with an unmarried mother and father (Statistics Finland 1992).

It is commonly known that in Finland consensual unions are mainly a prelude to marriage. Most people living in a consensual union prefer to have their children after they have married. Most pre-marital cohabitations end in marriage. The average length of the period of living in a consensual union before marrying has increased, however, from somewhat more than one year at the end of the 1960s to about two and a half years in the beginning of the 1980s (Statistics Finland 1989). At the same time there has been a weak tendency among young women towards a lower age at entering the first consensual union, about half a year from the 1950 s and 1960 s to the 1980 s (Lindgren et al. 1992). If time spent in a consensual union prior to marriage is prolonged and people prefer to have their first child after they have married, it is to be expected that this will raise the median age at first birth and decrease the total number of children in families. If a growing number of marriages start with pre-marital cohabitation $^{1}$, one could expect that the present Finnish nuptiality pattern will result in lower fertility. Even if the total number of children per family is low, higher age at first birth gives rise to a greater risk of sterility and unwillingness to have children. The Finnish nuptiality pattern could change, however, and start to resemble the Swedish and Danish life style, where the consensual union could be considered a social institution existing side by side with the institution of marriage where it is more common to have children in a consensual union. This would have a neutralizing effect on the fertility decrease that more consensual unions could be assumed to cause. It is most probable that we are moving towards the Swedish and Danish life style.

\section{The purpose}

In this article we will examine the fertility of consensual unions. We are mainly interested in knowing how consensual unions affect the childbearing of couples who live in a marriage which has been preceded by a period of pre-marital cohabitation. For the sake of comparison we will also include in our article marriages which have been contracted directly without pre-marital cohabitation as well as couples living in a consensual union throughout the whole period studied. We will also try to get an understanding of how pre-marital cohabitation affects fertility and reproduction.

This study is focused on women under the age of 30 when they started their first union $^{2}$. We have used quinquennial consensual union starting cohorts of women in the same way as marriage cohorts have commonly been used in nuptiality studies (e.g. Morgan and Rindfuss 1985, Thornton and Rogers 1987, Balakrishnan et al. 1987).

Many scholars consider membership of a birth cohort the most important explanation of observed behavioral changes (e.g. Ingelhart 1985, Leasthague 1987, Manting 1991). They emphasize that members of the same birth cohort share the same historical conditions and therefore are inclined to behave and react more or less in the same way. Finnäs (1993) has shown in a recently published paper that the intensity of start-

\footnotetext{
${ }^{1}$ In this article we use pre-marital, extra-marital and non-marital cohabitation as well as cohabiting without marriage and union without marriage as synonyms for consensual union.

${ }^{2}$ Of all women interviewed in the survey who had lived in a union, seven percent had started their union after the age of 30 or had had their first child before their first union.
} 
T a b le 1. The proportion of consensual unions of all unions by birth cohorts, agegroups and years of starting the union.

Birth cohort

\begin{tabular}{|c|c|c|c|c|}
\hline $17-19$ & $20-22$ & $23-25$ & $26-29$ & $\begin{array}{l}\text { Years of } \\
\text { starting the } \\
\text { union }\end{array}$ \\
\hline 26 & 23 & 41 & 44 & $1973-1978$ \\
\hline 46 & 56 & 60 & 60 & $1976-1981$ \\
\hline 67 & 68 & 73 & 79 & $1979-1984$ \\
\hline 83 & 81 & 76 & 79 & \\
\hline 82 & 83 & 83 & 82 & \\
\hline 92 & 91 & 90 & - & \\
\hline
\end{tabular}

$1947-1949$

$1950-1952$

$1953-1955$

$1956-1958$

$1959-1961$

$1962-1964$

Source: Finnäs 1993, 19.

ing with a consensual union is clearly connected to the birth cohort. The birth cohort born in 1950-1952 was in fact the first cohort in which it become more common to form a consensual union. In the following three-year cohorts the proportion starting a consensual union grows from cohort to cohort. It is interesting to note that in the first cohorts the proportion of extra-marital cohabitation increases with age or chronologically from the middle of the 1970 s (Table 1). In the last cohorts, on the contrary, the proportion is about the same in all age groups.

Prior to the 1970 s consensual unions were rather unusual and one could say that they were entered by couples belonging to special groups in society. It is very likely that the increasing popularity of forming consensual unions in the 1970 s was to a large extent a consequence of the change of norms in society; sexual liberation spread among the young generations, sexual relations were no longer considered permissible only in matrimonial cohabitation, free abortion was introduced, etc. Finnäs (1993) thinks that it was the large cohort born after the Second World War which started the new behavior of pre-marital cohabitation but he also points out that they happened to be in the right place at the right time. It seems to be quite obvious that the 1970 s forms a watershed in cohabitation behavior with even larger changes coming in the 1980s.

It should also be mentioned that Hoem and Hoem (1988) did not find in their work on the break-up of conjugal unions among Swedish women any significant separate influence when using union starting year in addition to birth cohorts.

In this article we use starting cohorts. We do not think that there would be any important differences between union formation cohorts and birth cohorts particularly with respect to the fact that our material concerns women who have started their union at less than 30 years of age.

The study deals with quinquennial cohorts who started living together after 1970, i.e. 1970-1974, 1975-1979 and 1980-1984. In the cohorts each consensual union is treated separately. Not all consensual unions could be followed for an equally long time, e.g. in the last cohort couples starting to cohabit at the end of 1984 could not be followed for more than five years ${ }^{3}$. The material used is from a survey made in $1989^{4}$.

${ }^{3}$ The length of the period each cohort has been studied depends on how long time the last oneyear group within each cohort could be followed. Consequently the period studied in the first cohort $(1970-1974)$ is 14 years, in the intermediate cohort (1975-1979) nine years and in the last one (19801984) five years.

${ }^{4}$ In the survey 4,155 women aged $22-51$ years and living in a household were interviewed. For further information on the survey see e.g. Timo Nikander, Naisen elämänkulku ja perheellistyminen: The woman's life course and the family formation. Population 1992:1. Helsinki: Statistics Finland, 1992. 
Fig u re 1. The age distribution of women aged under 30 years when starting their consensual union in 1970-1974, 1975-1979 and 1980-1984, by quinquennial age groups.

1970-74 cohort

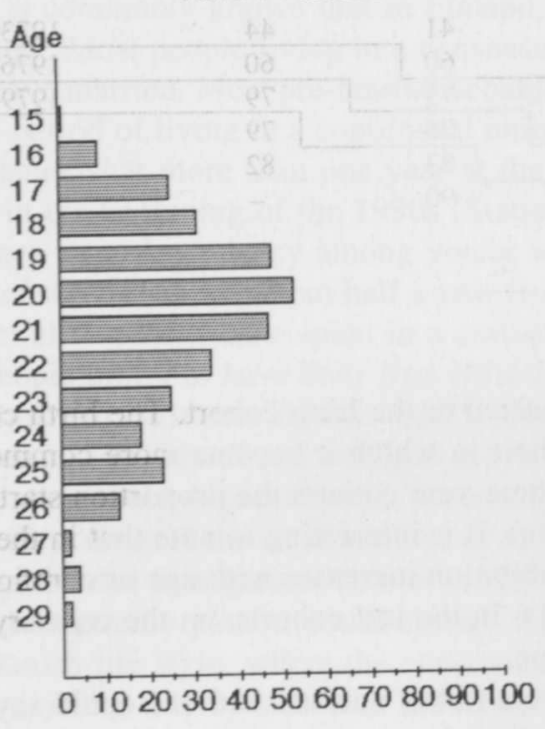

Median 20.5
1975-79 cohort

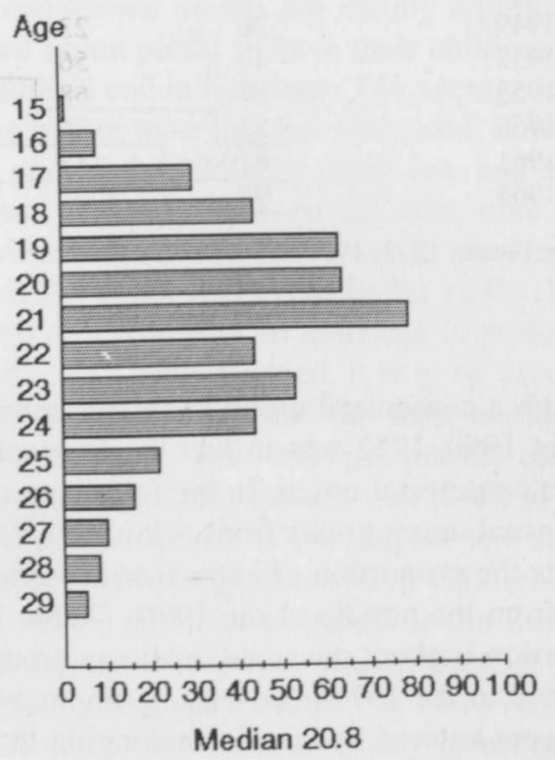

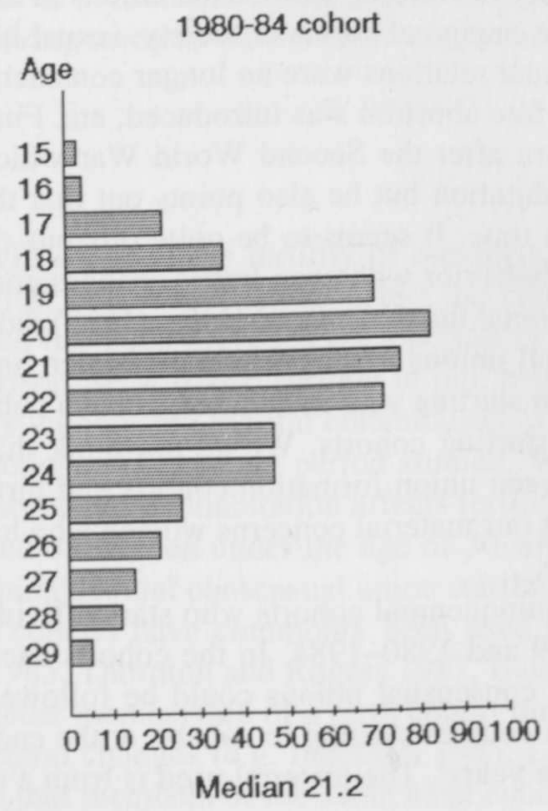

Source: Statistics Finland, Survey 1989.

\section{Some background data}

The three cohorts included in this study show that consensual unions became more and more common in all ages from cohort to cohort. On the whole the distribution by age was the same and the median starting age was 21 years in all cohorts (Figure 1). 
Most consensual unions end sooner or later in marriage. In the oldest cohort, those starting their first consensual union in 1970-1974, about 85 percent married, while the corresponding proportion was 73 percent among those who began cohabiting in 1975-1979 and 65 percent when the starting years were 1980-1984 (Lindgren et al. 1992). As the proportions depend on how long the cohort could be followed, a better way would be to compare proportions in consensual unions of the same duration in all the cohorts studied. The difference is somewhat less accentuated after e.g. five years, or 79 percent in the first cohort and 61 in the last one.

At the same time, as fewer consensual unions end in marriage dissolutions increase. After five years, seven percent of the first cohort studied had broken up; in the last cohort the proportion was almost three times as high, or 19 percent.

The length of time spent in a consensual union has increased clearly from the first cohort studied to the latest one (Table 2).

Of those who started their pre-marital cohabitation in 1970-1974 41 percent had ended their consensual union, mainly in marriage, within one year, while the corresponding proportion among those who formed a consensual union in 1980-1984 was only 26 percent. After four years, more than one fourth were living together in a consensual union in the last starting cohort but only one fifth in the first cohort.

In Finland the median age at giving birth to the first child was 26.4 years in 1989. The median age at birth in the three cohorts studied was somewhat lower, or between 24 and 25 years, obviously caused by the fact that these cohorts only included women who were under 30 years of age when starting their first union.

The age at first birth increases with the growing length of the pre-marital cohabitation. It is highest among those who have been living in a consensual union for more than four years and lowest in duration groups where the consensual union has lasted less than one year (Table 3). The age at first birth in all durations grows when going from first cohorts to the last one. Among those who started to cohabit in 1970-1974

$\mathrm{T}$ a b l e 2. The length of the duration of the first consensual unions which began in 1970-1974, 1975-1979 and 1980-1984 among women aged 15-29 years of age.

$\begin{array}{cccc} & 1970-1974 & 1975-1979 & 1980-1984 \\ -12 \text { months } & 41.0 & 35.6 & 26.5 \\ 13-24 ”-36 " & 21.1 & 20.0 & 19.7 \\ 25-36 & 12.5 & 11.0 & 14.1 \\ 37-48 \% & 6.4 & 9.1 & 11.1 \\ 49- & 19.0 & 24.3 & 28.6 \\ & 100.0 & 100.0 & 100.0\end{array}$

Source; Statistics Finland, Survey 1989.

$\mathrm{T}$ a b l e 3. The median age at birth of the first child of women with pre-marital cohabitation of different lengths, by cohorts according to time of entering cohabitation.

Starting cohort Length of pre-marital cohabitation (months)

$\begin{array}{cccccc} & 0-12 & 13-24 & 25-36 & 37-48 & 49- \\ 1970-1974 & 24.6 & 24.4 & 24.5 & 25.7 & 25.5 \\ 1975-1979 & 23.7 & 24.3 & 26.6 & 25.3 & 26.0 \\ 1980-1984 & 23.0 & 24.0 & 24.9 & 24.1 & 25.1\end{array}$

Source: Statistics Finland, Survey 1989. 
and had a pre-marital cohabitation of less than one year, the age at first birth was 24.6 years, and 25.5 if cohabitation had lasted for more than four years. The corresponding ages were 23.0 and 25.1 in the last cohort, those starting in 1980-1984.

At first glance the trend towards a lower age at first birth seems to be confusing, as the national mean age at first birth has increased from 24.0 in 1970 to 26.3 in 1989. The explanation for the lower starting age of consensual unions in the later cohorts is that the time during which they could be followed is shorter in later cohorts.

\section{First child}

We will begin our examination of the pattern of giving birth to the first child by comparing the childbearing of the directly married ${ }^{5}$ with those whose marriage was preceded by a pre-marital cohabitation. Here we will treat all those who started their partnership as a consensual union as one group. Further on, we will delve deeper and compare the frequency of births according to the length of the period in a consensual union. We will mostly use cumulative curves to show the fertility pattern.

There is a significant difference in the pattern of giving birth to the first child among women who married without any pre-marital cohabitation and those who started their life together with a consensual union. In unions which have started with pre-marital cohabitation, the first child could be born either before the marriage or after the couple has married ${ }^{6}$.

Childbearing intensity ${ }^{7}$ is much higher among directly married couples than among couples who started with extra-marital cohabitation; two or three times greater in all cohorts, sometimes even higher. Among the directly married, the cumulative childbearing curve rises steeply in the beginning and then gradually becomes more or less horizontal. Those who have experienced pre-marital cohabitation have an almost linearly growing curve (Figure 2 ).

After one year almost one half of the women who married without any previous extra-marital cohabitation had had their first child; 46 percent in the first cohort and 41 in the last one. The corresponding figure was much lower for those whose marriage was preceded by a period of pre-marital cohabitation or who lived in a consensual union during the whole time studied: 13 percent and 12 percent.

After five years almost 90 percent of the directly married women had given birth to their first child. At the same time only around 60 percent of women who lived or had lived in a pre-marital cohabitation had had their first child. The proportion was greatest in the first cohort and smallest in the last one, or 64 and 57 percent. In the intermediate cohort the proportion was 60 percent. The difference becomes smaller, the longer the cohort could be followed.

In the first cohort, at the end of the period or after 14 years, the proportion of first births reaches practically the same level as that of direct marriages, or 91 percent. In direct marriages the proportion was 95 percent. In the intermediate cohort, which could

\footnotetext{
${ }^{5}$ As shorter synonyms for "marriage not preceded by pre-marital cohabitation" we will subsequently use "directly married" or "direct marriage", borrowed from Leridon (1990).

${ }^{6}$ After having given birth to the first child or separated before giving birth the woman was removed from the data. The proportion of consensual unions which ended in separation before the birth of the first child was significantly smaller in the first cohort than in the following ones, or 6.1 percent (after 14 years). In the intermediate and the last cohort the proportions were 15.1 (after 9 years) and 16.4 percent (after 5 years).

${ }^{7}$ Separation before having a child has been treated as a censoring event when calculating the intensities.
} 
F i g u re 2. The cumulative proportion of women who have given birth to their first child after starting to cohabit, by starting cohorts.
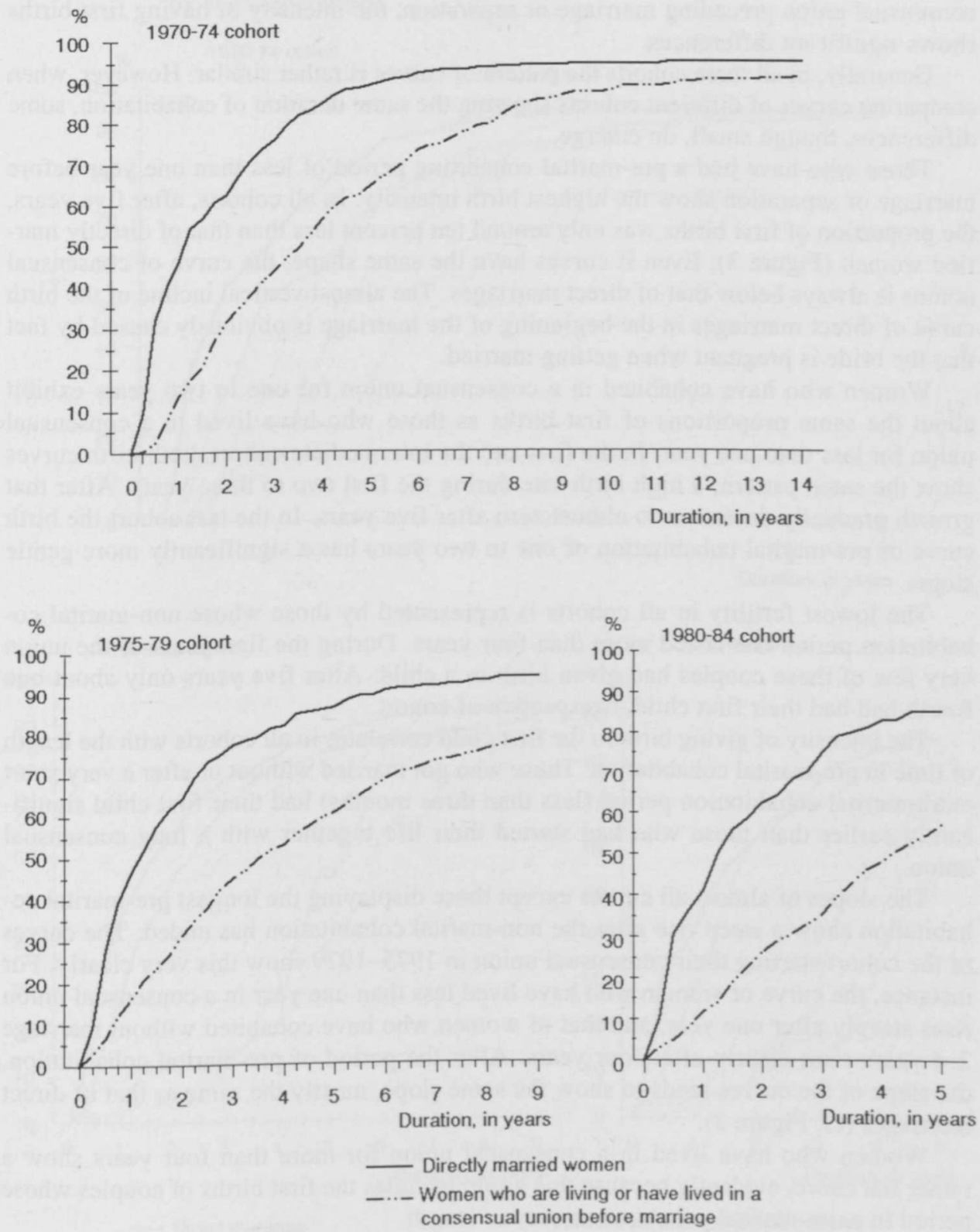

Source: Statistics Finland, Survey 1989.

be followed for nine years, the proportion reaches a level of 76 percent for those who started with a consensual union while that of the directly married was 93 percent. The last cohort has been left out from the comparison because the period it could be followed was so short.

Until now we have studied first births by dividing the material in two groups, women who have experienced pre-marital cohabitation and directly married women. This first overview of the intensity of having a child gives the impression that women 
who have lived in pre-marital cohabitation tend ultimately to have the same proportion of first births as the directly married.

However, when splitting up the material according to the length of time spent in consensual union preceding marriage or separation, the intensity of having first births shows significant differences.

Generally, in all three cohorts the pattern of curves is rather similar. However, when comparing curves of different cohorts showing the same duration of cohabitation, some differences, though small, do emerge.

Those who have had a pre-marital cohabiting period of less than one year before marriage or separation show the highest birth intensity. In all cohorts, after five years, the proportion of first births was only around ten percent less than that of directly married women (Figure 3). Even if curves have the same shape, the curve of consensual unions is always below that of direct marriages. The almost vertical incline of the birth curve of direct marriages in the beginning of the marriage is obviously caused by fact that the bride is pregnant when getting married.

Women who have cohabited in a consensual union for one to two years exhibit about the same proportions of first births as those who have lived in a consensual union for less than one year. In the first and the intermediate cohort, both birth curves show the same pattern; a high birth rate during the first two to three years. After that growth gradually decreases to almost zero after five years. In the last cohort the birth curve of pre-marital cohabitation of one to two years has a significantly more gentle slope.

The lowest fertility in all cohorts is represented by those whose non-marital cohabitation period has lasted more than four years. During the first years of the union very few of these couples had given birth to a child. After five years only about one fourth had had their first child, irrespective of cohort.

The intensity of giving birth to the first child correlates in all cohorts with the length of time in pre-marital cohabitation. Those who got married without or after a very short extra-marital cohabitation period (less than three months) had their first child significantly earlier than those who had started their life together with a long consensual union.

The slopes of almost all curves except those displaying the longest pre-marital cohabitation show a steep rise after the non-marital cohabitation has ended. The curves of the cohort starting their consensual union in 1975-1979 show this very clearly. For instance, the curve of women who have lived less than one year in a consensual union rises steeply after one year, and that of women who have cohabited without marriage 2-4 years rises clearly after four years. After the period of pre-marital cohabitation, the slope of the curves tends to show the same slope, mostly the same as that of direct marriages (cf. Figure 3).

Women who have lived in a consensual union for more than four years show a rather flat curve, evidently because this group includes the first births of couples whose period in extra-marital cohabitation vary in length.

The curves indicate rather clearly the well known fact that most Finnish couples prefer not to have children when living in a consensual union.

The highest proportion of primipara women is shown by the directly married women of the first cohort, or a total of 95 percent (Table 4). Those who had cohabited without marriage for less than two years reached the same proportion or even higher at the end of the period studied. A somewhat lower proportion was exhibited by those who had lived together without marriage for a period of more than three years.

In the intermediate cohort the tendency is the same as in the first cohort, even if the proportions are somewhat smaller. Unions with long extra-marital cohabitation include less couples with children or 78 percent. 
Figure 3. The proportion of first birth in direct marriages and marriages which started with pre-marital cohabitation of different length as well as in consensual unions which have continued during the whole period studied, by starting cohorts.
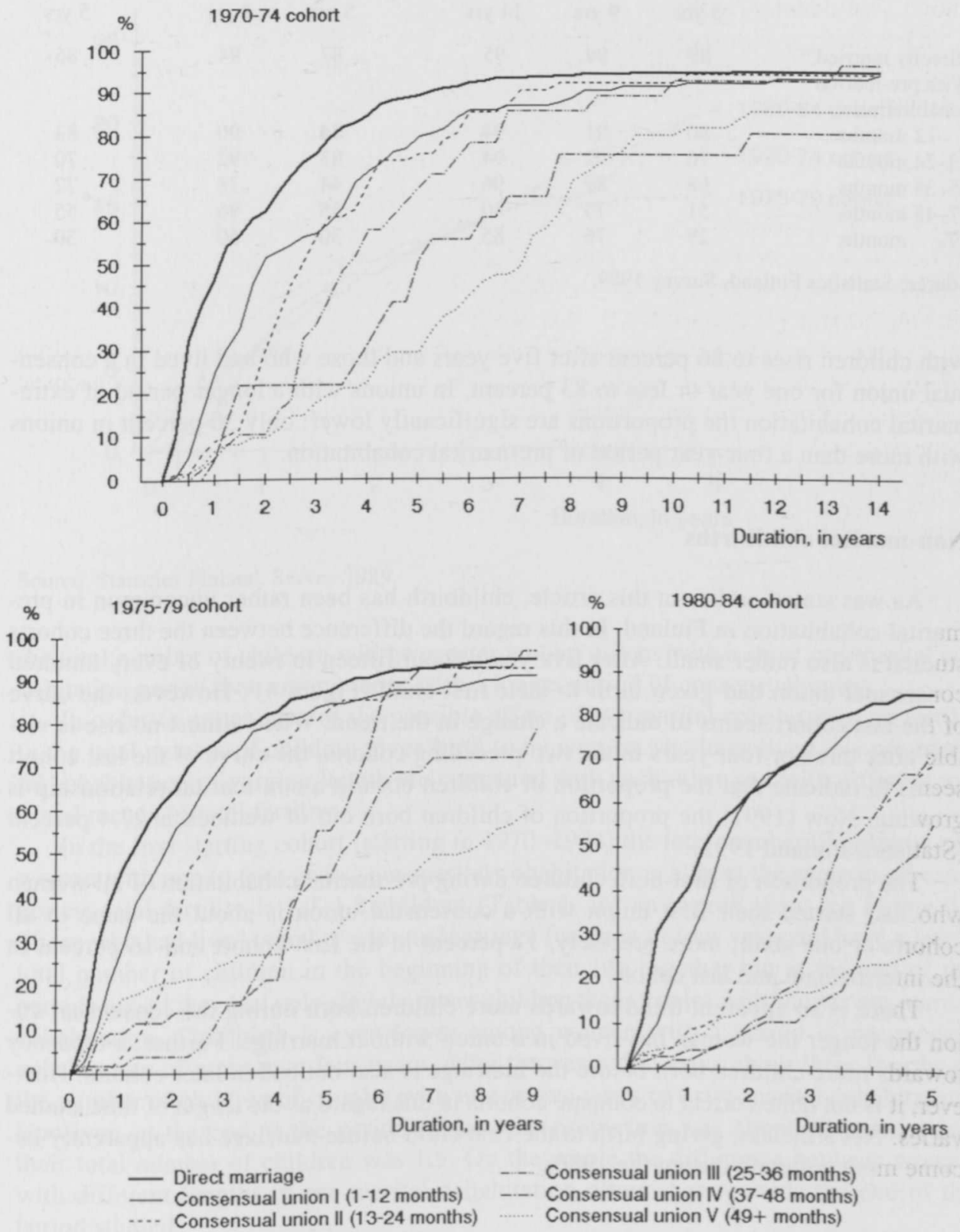

-. Consensual union III (25-36 months)

Consensual union N (37-48 months)

Consensual union V $(49+$ months)

Source: Statistics Finland, Survey 1989.

Information on the last cohort could not give reliable data on the final proportion of first births. Nevertheless, the curves of direct marriages and unions with less than one year of premarital cohabitation seem to be quite horizontal at the end of the period, indicating that the real final proportion will obviously not be much greater than the figures obtained after five years (cf. Figure 3). The proportion of direct marriages 
$\mathrm{T}$ a b l e 4. The proportion (percent) of first births after five years as well as the final proportion in starting cohorts.

\begin{tabular}{lcccccc} 
& \multicolumn{3}{c}{$1970-1974$} & \multicolumn{2}{c}{$1975-1979$} & $1980-1984$ \\
& $\begin{array}{c}\text { After } \\
5 \text { yrs }\end{array}$ & $\begin{array}{c}\text { After } \\
9 \text { yrs }\end{array}$ & $\begin{array}{c}\text { After } \\
14 \text { yrs }\end{array}$ & $\begin{array}{c}\text { After } \\
5 \text { yrs }\end{array}$ & $\begin{array}{c}\text { After } \\
9 \text { yrs }\end{array}$ & $\begin{array}{c}\text { After } \\
5 \text { yrs }\end{array}$ \\
& 89 & 94 & 95 & 87 & 94 & 86 \\
$\begin{array}{l}\text { Directly married } \\
\text { With pre-marital }\end{array}$ & & & & & & \\
cohabitation & 80 & 91 & 94 & 84 & 90 & 83 \\
-12 months & 76 & 92 & 94 & 83 & 92 & 70 \\
$13-24$ months & 68 & 89 & 96 & 44 & 78 & 72 \\
$25-36$ months & 51 & 75 & 80 & 55 & 96 & 55 \\
$37-48$ months & 29 & 76 & 85 & 30 & 60 & 30 \\
$49-\quad$ months & & & & & &
\end{tabular}

Source: Statistics Finland, Survey 1989.

with children rises to 86 percent after five years and those who had lived in a consensual union for one year or less to 83 percent. In unions with a longer period of extramarital cohabitation the proportions are significantly lower: only 30 percent in unions with more than a four-year period of pre-marital cohabitation.

\section{Non-marital childbirths}

As was stated earlier in this article, childbirth has been rather uncommon in premarital cohabitation in Finland. In this regard the difference between the three cohorts studied is also rather small. After five years about fifteen to twenty of every hundred consensual union had given birth to their first child (Figure 4$)^{8}$. However, the curve of the last cohort seems to indicate a change in the trend. When almost no rise is visible after three or four years in the two preceding cohorts, the curve of the last cohort seems to indicate that the proportion of children born in a non-marital relationship is growing. Now (1991) the proportion of children born out of wedlock is 27.4 percent (Statistics Finland 1993).

The proportion of first-born children during pre-marital cohabitation of all women who had started their first union with a consensual union is about the same in all cohorts or one sixth; more precisely, 17 percent in the first cohort and 16 percent in the intermediate and last cohort.

There is an apparent trend towards more children born during the consensual union the longer the woman has lived in a union without marriage. Further, a tendency towards more children born before the marriage is also noticed in later cohorts. However, it is not quite correct to compare cohorts in this regard as the length of time studied varies. Nevertheless, giving birth to the first child before marriage has apparently become more common during the 1980 s.

\section{Total number of children and pre-marital cohabitation}

The figures in the preceding paragraphs indicate clearly that the longer the premarital phase, the later the first child is born and the smaller the cumulative proportion of women giving birth to their first child. Consequently, one might assume that

\footnotetext{
${ }^{8}$ The figure is based solely on women who have given birth in a consensual union. Those who have married or separated before giving birth to a child have been considered as censoring events.
} 
Fig u re 4. The cumulative proportion of non-marital first births within five years of entering the consensual union, by starting cohorts.

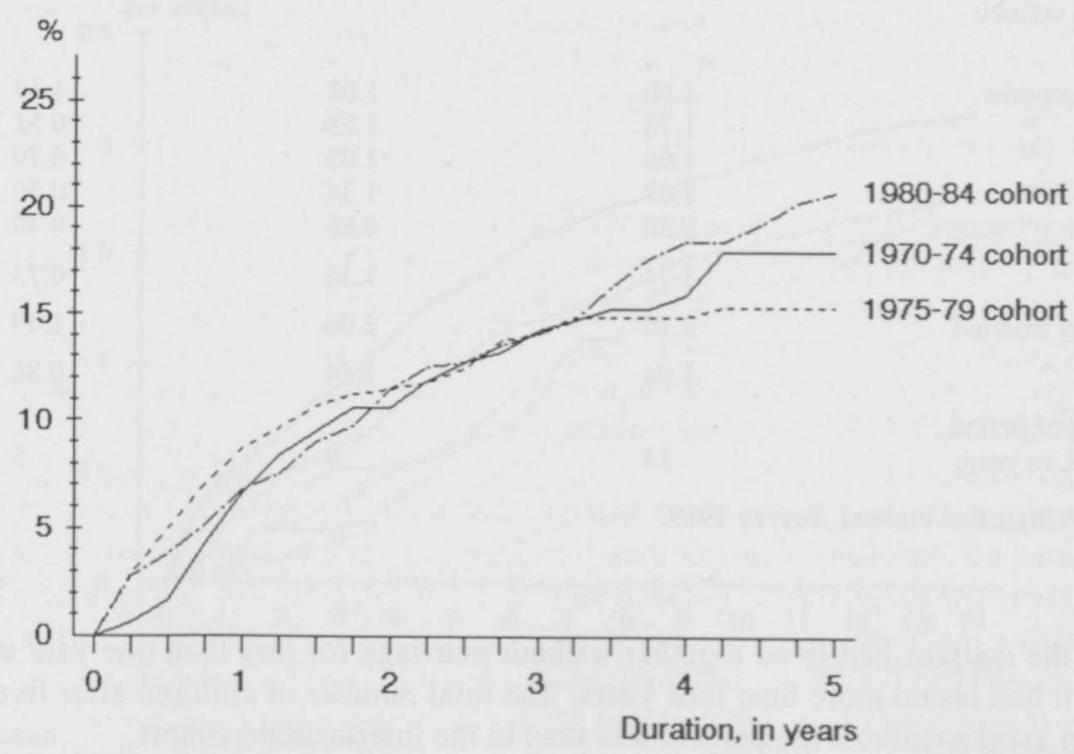

Source: Statistics Finland, Survey 1989.

the total number of children will be greater among unions with a short pre-marital cohabitation period than among those with a longer period of consensual union.

In order to get an idea of the possible effect of pre-marital cohabitation on fertility the total number of children given birth to by women who have lived in a pre-marital cohabitation of varying length are compared with each other and with different national means of total fertility.

In the first starting cohort (starting in 1970-1974) the total number of children per woman with one to four years' pre-marital cohabitation is almost the same in all categories; total fertility is $1.7-1.8$ children (Table 6 , for an overall view see Figure 5). Those who had lived together without marriage for three or four years did have a lower total number of children in the beginning of their life together but at the end of the period studied they had only slightly fewer children than couples with shorter pre-marital cohabitation. Childbirth is even lower among women with a period of pre-marital cohabitation of more than four years. After ten years they have about three fourths of the number of children of couples with one or two years of extra-marital cohabitation. However, at the end of the period studied the proportion was about 80 percent and their total number of children was 1.5 . On the whole the difference between women with different lengths of pre-marital cohabitation diminishes towards the end of the period studied.

In the intermediate cohort (starting in 1975-1979), which has been followed for nine years, the tendency towards a lower total number of children becomes even more accentuated when the period of pre-marital cohabitation lengthens. Women with the shortest pre-marital cohabitation have 1.7 children. The longer the pre-marital cohabitation, the lower the total number of children. Women with the longest period of extra-marital cohabitation have on average less than one child or 0.9 children.

The tendency is the same in the last cohort (starting in 1980-1984) as in the intermediate cohort, at least during the five years this cohort could be studied: 1.1 children 
T a b l e 6. Total number of children and the length of pre-marital cohabitation period, by starting cohorts.

$\begin{array}{lccc}\begin{array}{l}\text { Length of pre- } \\ \text { marital cohabi- } \\ \text { tation }\end{array} & 1970-1974 & 1975-1979 & 1980-1984 \\ 0-12 \text { months } & 1.80 & 1.68 & 1.13 \\ 13-24 \% & 1.78 & 1.55 & 0.81 \\ 25-36 \% & 1.66 & 1.06 & 0.70 \\ 37-48 \quad & 1.67 & 1.34 & 0.50 \\ 49- & 1.50 & 1.36 & 0.40 \\ \text { Total } & 1.71 & 2.06 & 0.73 \\ \text { Directly married } & 2.15 & 1.54 & 1.49 \\ \text { All } & 1.94 & & 0.86 \\ \text { Length of period } & & 9 & 5\end{array}$

Source: Statistics Finland, Survey 1989.

when the couples had lived together without marriage for less than one year and 0.4 when it had lasted more than four years. The total number of children after five years was on average almost ten percent less than in the intermediate cohort.

In all the three cohorts, directly married couples give birth to significantly more children than those who started with a consensual union, or 2.2 in the first cohort, 2.1 in the intermediate and 1.5 in the last cohort. The tendency towards greater differences in later cohorts could be due to the shorter period during which couples could be studied.

Principally, the total number of children follows the same pattern as that of the birth of the first child shown in earlier figures and tables.

Only the first cohort could be studied long enough to give almost complete information on the final number of children. In this cohort the total number of children seems to be rather independent of the length of pre-marital cohabitation, except for those with a pre-marital cohabitation of longer than four years. They clearly have fewer children. However, this cohort might represent a more old-fashioned way of thinking than the subsequent ones. The last cohort again could be studied for too short a time to give a reliable figure of the total number of children.

Consequently, when comparing the total number of children women included in the survey had had with corresponding national means, the intermediate cohort would be the best subject for the comparison. Even if this cohort could not be studied longer than nine years, it represents todays's attitudes and thinking more than the preceding one. This cohort had reached a median age of 33 years at the end of the period studied and could be considered old enough to give a reliable picture of the total number of children'. lows:

${ }^{9}$ When the interview was carried out the age distribution of the $1975-1979$ cohort was as fol-

\begin{tabular}{|c|c|c|}
\hline \multicolumn{2}{|c|}{$22-24$ years of age } & $0.3 \%$ \\
\hline $25-29$ & -"- & $19.5 "$ \\
\hline $30-34$ & -"- & 60.5 \\
\hline $35-39$ & -"- & 18.7 \\
\hline $40-44$ & -"- & 1.0 \\
\hline
\end{tabular}


Fig u re 5. The total number of children according to the length of pre-marital cohabitation.
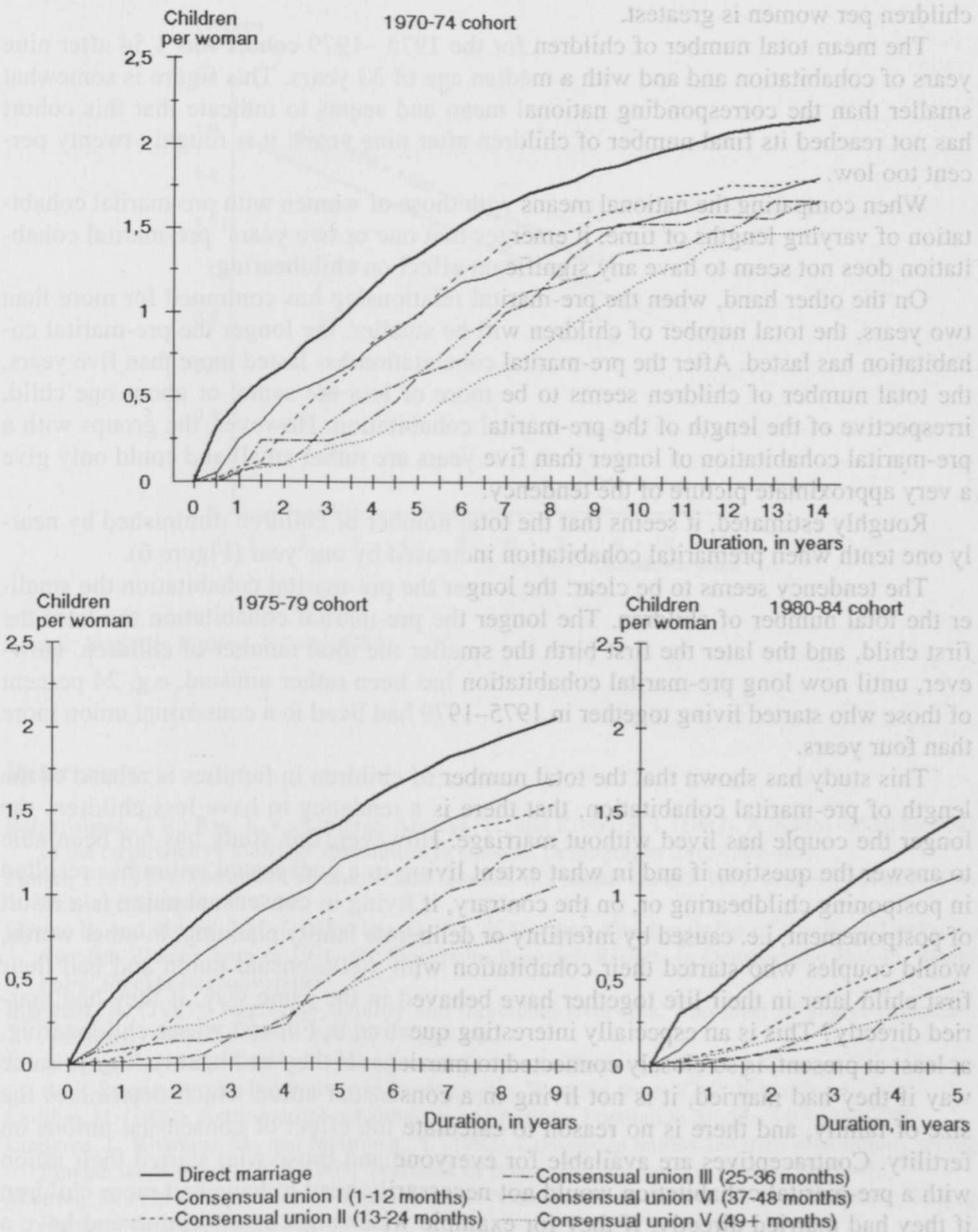

As eighty percent of the $1975-1979$ cohort was born in the $1950 \mathrm{~s}$, it is feasible to compare the cohort mean with the national mean of women born in the same decade. As the median age of the cohort was 33 years when the survey was carried out in 1989 , the cohort fertility is compared with the fertility of the whole country at 35 years of age.

The yearly national mean of total fertility varied from 1.67 to $1.70^{10}$ among women born in the 1950s and now aged 35 years. Another figure of interest in this context is the total number of children under 18 years of age in 1990: it was 1.81 per women 
aged 35-39 years and living in a marriage or in a consensual union (Statistics Finland, 1992a $)^{11}$. At this age childbearing could be considered to have ended with almost all children still living at home. It is also the age group where the number of children per women is greatest.

The mean total number of children for the $1975-1979$ cohort was 1.54 after nine years of cohabitation and and with a median age of 33 years. This figure is somewhat smaller than the corresponding national mean and seems to indicate that this cohort has not reached its final number of children after nine years; it is roughly twenty percent too low.

When comparing the national means with those of women with pre-marital cohabitation of varying lengths of time, it emerges that one or two years' pre-marital cohabitation does not seem to have any significant effect on childbearing.

On the other hand, when the pre-marital relationship has continued for more than two years, the total number of children will be smaller, the longer the pre-marital cohabitation has lasted. After the pre-marital cohabitation has lasted more than five years, the total number of children seems to be more or less the same, or about one child, irrespective of the length of the pre-marital cohabitation. However, the groups with a pre-marital cohabitation of longer than five years are rather small and could only give a very approximate picture of the tendency.

Roughly estimated, it seems that the total number of children diminished by nearly one tenth when premarital cohabitation increased by one year (Figure 6).

The tendency seems to be clear: the longer the pre-marital cohabitation the smaller the total number of children. The longer the pre-marital cohabitation the later the first child, and the later the first birth the smaller the total number of children. However, until now long pre-marital cohabitation has been rather unusual, e.g. 24 percent of those who started living together in 1975-1979 had lived in a consensual union more than four years.

This study has shown that the total number of children in families is related to the length of pre-marital cohabitation, that there is a tendency to have less children, the longer the couple has lived without marriage. However, this study has not been able to answer the question if and in what extent living in a consensual union has resulted in postponing childbearing or, on the contrary, if living in consensual union is a result of postponement, i.e. caused by infertility or deliberate family planning. In other words, would couples who started their cohabitation with a consensual union and had their first child later in their life together have behaved in the same way, if they had married directly? This is an especially interesting question in Finland where childbearing, at least at present, is so closely connected to marriage. If they had behaved in the same way if they had married, it is not living in a consensual union which determines the size of family, and there is no reason to calculate the effect of consensual unions on fertility. Contraceptives are available for everyone and those who started their union with a pre-marital cohabitation would not necessarily need to have had more children if they had married directly. If they for example wish to get an education and have a career, their opportunities for scheduling childbearing are as good in marriage as in a consensual union. Apparently, those who married directly are couples for whom family and children are very essential in life. We hope that we will be able to examine this question more thoroughly in a later article.

${ }^{10}$ The figures on total fertility are calculated by using yearly birth statistics from 1965 (Statistics Finland, OSF VI A 127-). The total fertility of those born during the last three years of the 1950 s has been estimated.

"When calculating the total number of children per women, one-parent families are left out from the family statistics which include married couples with and without children, couples living together without marriage with and without children and one parent families. 
F i g u r e 6. Total number of children (total fertility rate, TFR) as a function of length of pre-marital cohabitation in starting cohort 1975-1979.

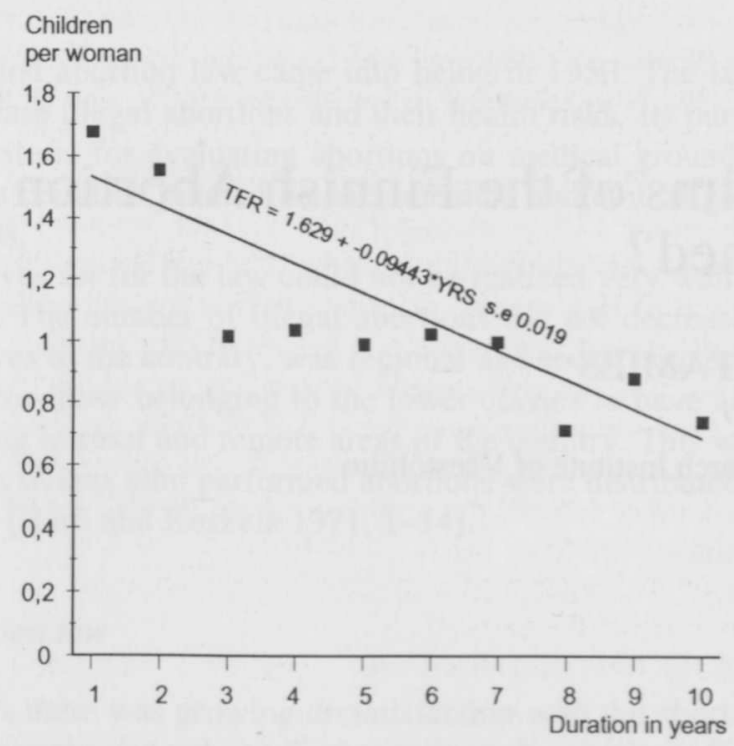

Source: Statistics Finland, Survey 1989.

\section{References}

Balakrishnan, T.R.; Rao, K.V.; Lapierre-Aamcyk, E., and Krotki, K.J. (1987). A hazard model analysis of the covariates of marriage dissolution in Canada. Demography 24(3):395-406.

Finnäs, F. (1993). Formation of unions and families in Finnish cohorts born 1938-67. Studies 197. Helsinki: Statistics Finland.

Hoem, B. and Hoem, J.M. (1988). Dissolution in Sweden: The Break-Up of Conjugal Unions to Swedish Women born in 1936-60. Stockholm Research Reports in Demography No. 45. Stockholm: Stockholms universitet.

Ingelhart, R. (1985). Aggregate stability and individual-level-flux: The level of analysis paradox. American Political Science Review 75:880-900.

Leasthague, R. (1987). Cultural Dynamics and Economic Theories of Fertility Change. Vrije Universiteit, Interuniversity Programme in Demography, Working paper 87-7. Brussels.

Leridon, H. (1990). Extra-marital cohabitation and fertility. Population Studies 44(3):469-487.

Lindgren, J.; Ritamies, M., and Miettinen, A. (1992). Consensual unions and their dissolutions among Finnish women born 1938-1969. Yearbook of Population Research in Finland 30:33-43.

Manting, D. (1991). First Union Formation in the Netherlands. Postdoctorale Onderzoekersopleiding Demografie-paper No.5. Amsterdam.

Morgan, S.P. and Rindfuss, R.R. (1985). Marital disruption. Structure and temporal dimensions. American Journal of Sociology 90:1055-1077.

Nikander, T. (1992). Naisen elämänkulku ja perheellistyminen; The woman's life course and the family formation. Population 1992:1. Helsinki: Statistics Finland.

Statistics Finland (1989). Material received in the interview survey among women aged 22-51 in 1989.

Statistics Finland (1992). Perheet 1990: Families 1990. Population 1992:7. Helsinki.

Statistics Finland (1993). Statistical Yearbook of Finland 1993. Helsinki.

Thornton, A. and Rogers, W.L. (1987). The influence of individual and historical time on marital dissolution. Demography 24(1):1-22. 